\title{
Local Resections and Prosthetic Reconstructions in Solitary Bone Metastases of the Limbs According to Histotypes
}

\section{Maccauro G ${ }^{1}$, Andrea Piccioli ${ }^{2}$, Sebastiano Barreca ${ }^{3}$, Domenico Fenga ${ }^{3}$ and Michele Attilio Rosa ${ }^{3 \star}$}

${ }^{1}$ Musculoskeletal Oncology Unit, Department of Geriatrics, Neurosciences and Orthopedics, University Hospital "Agostino Gemelli", Catholic University of the Sacred Heart School of Medicine, Largo A. Gemelli 1, 00168, Rome, Italy

${ }^{2}$ Orthopedics Oncology, "Palazzo Baleani", Azienda Policlinico Umberto I, 00161 Rome, Italy

${ }^{3}$ Department of Biomedical and Dental Sciences and Morphofunctional Imaging, School of Orthopaedics and Traumatology, University Hospital "Gaetano Martino",

University of Messina, Via Consolare Valeria 1, 98100, Messina, Italy

\begin{abstract}
Patients with a solitary bone metastasis have a different prognosis according to primary tumor histotype. Surgeon has to consider this parameter when performing operations.

A good prognosis means a long survivorship, high functional demands, long lasting treatment and, overall, a quick rehabilitation program.

The study is on 36 patients with solitary bone metastasis from different Histotypes (Breast cancer, Kidney Cancer and Thyroid Cancer) which have been treated by resection and prostheses.

Clinical findings demonstrated that resections and prosthetic reconstructions are the gold standard to help surgeon to obtain the best results. Adjuvant systemic or local therapy may help when feasible.
\end{abstract}

Keywords: Metastasis; Bone resection; Prosthesis

\section{Introduction}

Some tumors can have a long lasting prognosis, so metastatic patients survival is different according to Histotypes. By the time we tried to find an mutual agreement to classify and treat properly bone metastases [1,2].

Grimer et al. [3] in a work in 1992 said "The average survival rate after the endoprosthetic replacement was 14.7 months and this varies with the primary tumor."

Capanna et al. [4] demonstrated survival differences between Histotypes (Table 1).

This classification permits to divide tumors in 3 prognostic groups (less than 1-year survival, between 1 and 2 years and over 2 years) with a different value score. Also they divided metastatic patients in 4 classes (Table 2).

In a more recent study from Piccioli et al. [5] was developed a clinical decision support tool, capable of estimating the likelihood of survival at 3 and 12 months following surgery for patients with operable skeletal metastases.

A good prognosis is a central parameter in considering a radical surgery for solitary bone metastases treatment.

\section{Materials and Methods}

In the current study only class 1 patients were considered. A series of 36 patients with solitary bone metastasis ( 28 proximal femurs and 8 proximal humerus), treated between 1998 and 2013, was considered according to primary tumor histotype: 25 adjuvant responder Breast cancer, 6 Kidney Cancer and 5 differentiated Thyroid Cancer. 30 female and 6 male. Mean age was 68 years (52-80). Mean follow-up was 18 months (6-72). Exclusion criteria were: multiple metastases, serious comorbidities and Class 2-3-4 patients.

All patients received a needle/open biopsy which confirmed the primary tumor histotypes. Resections were performed about 2 weeks after biopsy. Kidney metastases were embolized $24-48 \mathrm{~h}$ before surgery. Modular tumoral prostheses were positioned. In 20 cases

\begin{tabular}{|c|c|}
\hline survival & sources of metastasis \\
\hline \multirow{6}{*}{ less than 1 year ( 1 point) } & Unknown \\
\hline & Melanoma \\
\hline & Lung \\
\hline & Pancreas \\
\hline & Thyroid (undifferentiated) \\
\hline & Stomach \\
\hline \multirow{4}{*}{ One to two years ( 3 points) } & Colon \\
\hline & Breast (not responding to adjuvants) \\
\hline & Liver \\
\hline & Uterus (responding to adjuvants) \\
\hline \multirow{7}{*}{ Over two yeards (6 points) } & Thyroid (differentiated) \\
\hline & Myeloma \\
\hline & Lymphoma \\
\hline & Breast (responding to adjuvants) \\
\hline & Rectum \\
\hline & Prostate \\
\hline & Kidney \\
\hline
\end{tabular}

Table 1: Prognosis and histotype.

${ }^{*}$ Corresponding author: Michele Attilio Rosa, School of Orthopaedics and Traumatology, University of Messina, "Gaetano Martino" University Hospital , Messina, Italy, Tel:00390902213040; Fax: 00390902934567; E-mail: mattilio51@gmail.com

Received August 28, 2015; Accepted March 03, 2016; Published March 08, 2016 Citation: Maccauro G, Piccioli A, Barreca S, Fenga D, Rosa MA (2016) Local Resections and Prosthetic Reconstructions in Solitary Bone Metastases of the Limbs According to Histotypes. J Integr Oncol 5: 161. doi:10.4172/23296771.1000161

Copyright: (c) 2016 Maccauro G, et al. This is an open-access article distributed under the terms of the Creative Commons Attribution License, which permits unrestricted use, distribution, and reproduction in any medium, provided the original author and source are credited. 
Citation: Maccauro G, Piccioli A, Barreca S, Fenga D, Rosa MA (2016) Local Resections and Prosthetic Reconstructions in Solitary Bone Metastases of the Limbs According to Histotypes. J Integr Oncol 5: 161. doi:10.4172/2329-6771.1000161

a polyethylenterephtalate mesh (Trevira Tube ${ }^{\mathrm{R}}$ ) [6] was used to help insert muscles on implant (Figures $1 \mathrm{a}$ and $1 \mathrm{~b}$ ).

Shoulders remained 20 days in a tutor, then started rehabilitation; Hip started walking in 2 postoperative days with 2 clutches and without bearing and 2 weeks after started walking with progressive bearing on the affected limb.

The Muscoloskeletal Tumor Society Score (MTSS) [7] was performed in postoperative period to evaluate results.

About one month after surgery, patients with thyroid metastases got radioactive iodine therapy and patients with breast metastases received hormonal therapy, when feasible, or chemotherapy if they didn't get response. Kidney metastases didn't receive chemotherapy, because of the poor reaction to chemotherapy.

\section{Results}

Mean MTSS was 72\% (34\%-90\%). Complications were represented by delayed wound closure in 2 cases with superficial infection in 1 case. Wound surgical revision and targeted antibiotic therapy. There were no perioperative deaths. Best clinical results were obtained in patients with a high resection above gluteus maximus insertion in proximal femur (Figures $2 \mathrm{a}$ and $2 \mathrm{~b}$ ) and above deltoid insertion in proximal humerus (Figures 3a-3c).

Figure 2a shows MRI of a kidney metastasis in left proximal femur and Figure $2 \mathrm{~b}$ shows the post-op X-Ray.

Figure 3a shows the pre-op X-Ray image of a thyroid metastasis in left humerus, Figure $3 \mathrm{~b}$ shows the post-operative X-Ray and Figure $3 c$ demonstrates good clinical results. Table 3 explain survival for each histotype.

\begin{tabular}{|c|l|}
\hline class & $\begin{array}{l}\text { Solitary metastatic lesion } \\
\text { Primary with good prognosis (well-differentiated thyroid, prostate, breast } \\
\text { sensitive to adjuvants, rectum, clear-call renal, lymphoma, myeloma) } \\
\text { Interval over three years since detection of the primary }\end{array}$ \\
\hline 2 & Pathological fracture at any site \\
\hline 3 & Impending fracture in a major weight-bearing bone \\
\hline 4 & $\begin{array}{l}\text { Osteoblastic lesions at all sites } \\
\text { Osteolytic or mixed lesions in non-structural bones (fibula, rib, sternum, } \\
\text { clavicle) } \\
\text { Osteolytic lesion with no impending fracture in major weight-bearing } \\
\text { bone } \\
\text { Lesions of the wing of the ilium, anterior pelvis or scapula excluding } \\
\text { class-1 patients }\end{array}$ \\
\hline
\end{tabular}

Table 2: Classes of metastatic patients.

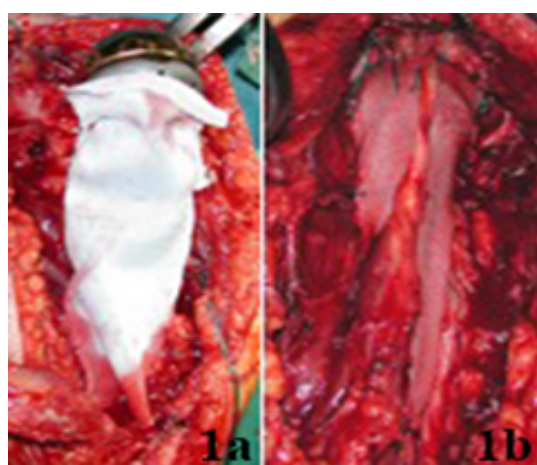

Figure 1: Trevira Tube. a: Mesh positioning; b: Muscles insertion on mesh.

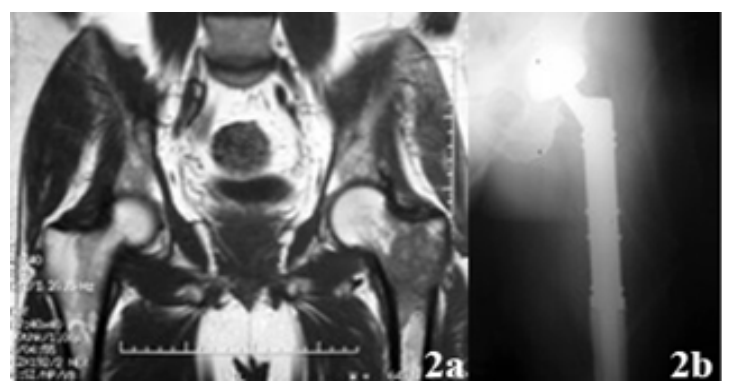

Figure 2: Gluteus maximus insertion. a: Shows MRI of a kidney metastasis in left proximal femur; b: Shows the post-op X-Ray.
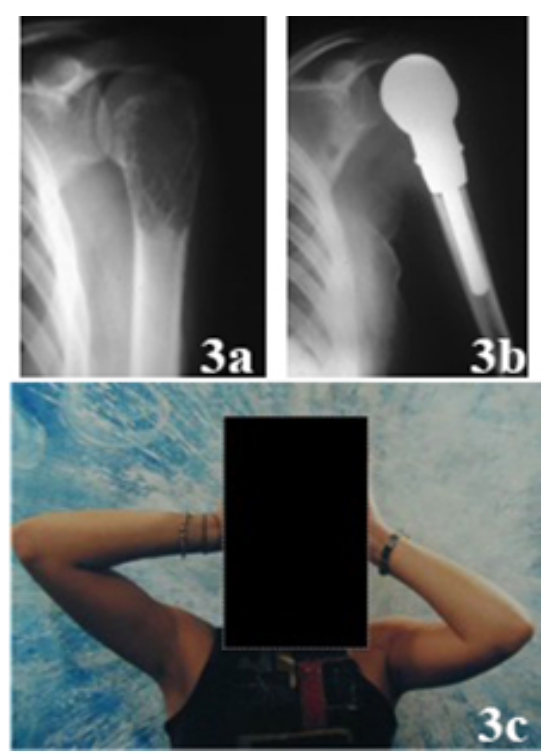

Figure 3: Deltoid insertion. a: Shows the pre-op X-Ray image of a thyroid metastasis in left humerus; b: Shows the post-operative X-Ray; 3c: Demonstrates good clinical results.

\begin{tabular}{|c|c|c|c|c|c|}
\hline Survival & $<\mathbf{1 2}$ months & $\mathbf{2 4}$ months & $\mathbf{3 6}$ months & $\mathbf{4 8}$ months & $>\mathbf{6 0}$ months \\
\hline Thyroid & & 1 & 1 & 1 & 2 \\
\hline Kidney & & 1 & 1 & 2 & 2 \\
\hline Breast & 6 & 4 & 2 & 8 & 5 \\
\hline
\end{tabular}

Table 3: Survival for each histotype.

Resection and prosthetic replacement is the best option to get quick good functional and long lasting results in metastatic patients with good prognosis according to histology (class 1). Sørensen et al. [8] support there is no more incidence in death rate and surgical revision in prosthetic replacement compared with other technique.

Grimer et al. [9] concluded "that endoprosthetic replacement for bony metastases is an effective palliative procedure for a selected group of patients".

\section{References}

1. Biagini R, Brach del Prever E, Capanna R, Denaro V, Fazioli F, et al. (2012) Bone metastases: treatment strategies. GIOT 38: 177-187.

2. Campanacci DA, Daolio P, Gasbarrini A, Ippolito V, Maccauro G, et al. (2014) Guidelines SIOT: The Treatment of bone metastases in the appendicular skeleton. GIOT 40: 1-15. 
Citation: Maccauro G, Piccioli A, Barreca S, Fenga D, Rosa MA (2016) Local Resections and Prosthetic Reconstructions in Solitary Bone Metastases of the Limbs According to Histotypes. J Integr Oncol 5: 161. doi:10.4172/2329-6771.1000161

3. Chan D, Carter SR, Grimer RJ, Sneath RS (1992) Endoprosthetic replacement for bony metastases. Ann R Coll Surg Engl 74: 13-18.

4. Capanna R, Campanacci DA (2001) The treatment of metastases in the appendicular skeleton. J Bone Joint Surg Br 83: 471-481.

5. Piccioli A, Spinelli MS, Forsberg JA, Wedin R, Healey JH, et al. (2015) How do we estimate survival? External validation of a tool for survival estimation in patients with metastatic bone disease-decision analysis and comparison of three international patient populations. BMC Cancer 22: 415-424.

6. Gosheger G, Hillmann A, Lindner N, Rödl R, Hoffmann C, et al. (2001) Soft tissue reconstruction of megaprostheses using a trevira tube. Clin Orthop Relat Res 393: 264-271
7. Enneking WF, Dunham W, Gebhardt MC, Malawar M, Pritchard DJ (1993) A system for the functional evaluation of reconstructive procedures after surgical treatment of tumors of the musculoskeletal system. Clin Orthop Relat Res 286: 241-246.

8. Sørensen MS, Gregersen KG, Grum-Schwensen T, Hovgaard D, Petersen MM (2013) Patient and implant survival following joint replacement because of metastatic bone disease. Acta Orthop 84: 301-306.

9. Chan D, Carter SR, Grimer RJ, Sneath RS (1992) Endoprosthetic replacement for bony metastases. Ann R Coll Surg Engl 74: 13-18. 